\title{
Canis familiaris allergen Can f 7: Expression, purification and analysis of $B$ cell epitopes in Chinese children with dog allergies
}

\author{
RUI-QI WANG ${ }^{1 *}$, YU-JIE WANG ${ }^{2,3^{*}}$, ZHI-QIANG XU ${ }^{2 *}$, YAN-JUN ZHOU ${ }^{2}$, \\ MENG-DACAO ${ }^{2}$, WEI ZHU ${ }^{2}$, JIN-LYU SUN ${ }^{1}$ and JI-FU WEI ${ }^{2}$ \\ ${ }^{1}$ Department of Allergy, Peking Union Medical College Hospital, Peking Union Medical College and \\ Chinese Academy of Medical Sciences, Beijing Key Laboratory of Precision Medicine for Diagnosis and \\ Treatment on Allergic Diseases, Beijing 100730; ${ }^{2}$ Research Division of Clinical Pharmacology, \\ ${ }^{3}$ Department of Critical Care Medicine, The First Affiliated Hospital of \\ Nanjing Medical University, Nanjing, Jiangsu 210029, P.R. China
}

Received July 11, 2018; Accepted January 2, 2019

DOI: $10.3892 / \mathrm{ijmm} .2019 .4065$

\begin{abstract}
Dogs are a major source of indoor allergens. However, the prevalence of dog allergies in China remains unclear, especially in children. In the present study, Can $\mathrm{f}$ 7 , a canine allergen belonging to the Niemann pick type $\mathrm{C} 2$ protein family, was selected to study its sensitization rate in Chinese children with dog allergies. The Can $\mathrm{f} 7$ gene was subcloned into a pET-28a vector and expressed in Escherichia coli BL21 (DE3) cells. Recombinant Can f 7 was purified by nickel affinity chromatography, identified by SDS-PAGE electrophoresis, and had its allergenicity assessed by western blot, ELISA and basophil activation tests. Through a series of bioinformatical approaches, B-cell epitopes, secondary structures, and 3 dimensional (3D) homology modeling of Can $\mathrm{f} 7$ were predicted. The activity of the B cell epitopes was verified by ELISA. The recombinant $\mathrm{Can} \mathrm{f} 7$ showed a distinct band with a molecular weight of $14 \mathrm{kDa}$. Six of 20 sera from dog-allergic children reacted positively to the Can f 7 . Can $\mathrm{f} 7$ induced an $\sim 4.0$-fold increase in cluster of differentiation 63 and $\mathrm{C}-\mathrm{C}$ motif chemokine receptor $\mathrm{R} 3$ expression in basophils sensitized
\end{abstract}

Correspondence to: Professor Jin-Lyu Sun, Department of Allergy, Peking Union Medical College Hospital, Peking Union Medical College and Chinese Academy of Medical Sciences, Beijing Key Laboratory of Precision Medicine for Diagnosis and Treatment on Allergic Diseases, No. 1 Shuaifuyuan Wangfujing, Dongcheng, Beijing 100730, P.R. China

E-mail: sunj15@yahoo.com

Professor Ji-Fu Wei, Research Division of Clinical Pharmacology, The First Affiliated Hospital of Nanjing Medical University, 300 Guangzhou Road, Nanjing, Jiangsu 210029, P.R. China

E-mail: weijifu@hotmail.com

${ }^{*}$ Contributed equally

Key words: Can f 7, canine allergy, B cell epitope, Chinese children with the serum of dog-allergic children compared with those of non-allergic controls. The secondary structure analysis showed that Can $\mathrm{f} 7$ contains $6 \beta$-sheets. Five B cell epitopes of Can $\mathrm{f} 7$ were predicted, and two of these were confirmed by ELISA. These results indicate that Can $\mathrm{f} 7$ is an important canine allergen in Chinese children and provide novel data for further research concerning the use of Can $\mathrm{f} 7$ in the diagnosis and treatment of Chinese children with canine allergy symptoms.

\section{Introduction}

Immunoglobin (Ig)E-associated inhalational allergies are the most common allergy diseases, affecting $>25 \%$ of the world's population. Allergy symptoms include asthma, rhinitis, eczema and even life-threatening systemic allergic reaction. Allergies to furred animals, especially dogs and cats, are key factors in the development of rhinitis and asthma (1-3). Dogs are considered family pets worldwide. However, even if there is no dog in a person's house, canine allergens can also be found in schools and other public places as they can be carried on clothes, making them almost impossible to avoid. Canine allergens can cause symptoms ranging from rhinoconjunctivitis to severe asthma attacks $(4,5)$. In one large study conducted in a European population, $27 \%$ of people with suspected allergic disease had a positive skin prick test when exposed to canine extract (6). In a population-based cross-sectional study in Germany, up to $9 \%$ of children and adolescents were canine dandruff-susceptible, consistent with data obtained from the Swedish birth cohort BAMSE $(7,8)$.

To date, seven dog allergens have been identified (www. allergen.org). Among these allergens, Can f 1 is a lipocalin, which is secreted from canine sebaceous glands and is found in dog hair and dander as well as saliva; it is considered a major canine allergen (9). Additionally, other known allergens include albumin (Can f 3) (10), prostatic kallikrein (Can f 5) (11) and lipocalin [Can f 2 (12), Can f 4 (13) and Can f 6 (14); these show various molecular weights ranging from 16 to $69 \mathrm{kDa}$. Can $\mathrm{f} 7$ was initially identified from canine 
allergen testing extracts by sequencing a distinct protein from Coomassie-stained 2 dimension (2D)-PAGE gels. It belongs to the Niemann pick type C2 protein family and reportedly shows $16.9 \%$ sensitivity in dog-sensitized subjects (15). With the rapid increase in the number of pet dogs, several typical allergic diseases caused by dog allergens, such as asthma, atopic dermatitis and eczema, are becoming increasingly frequent in China (16). Li et al (17) discovered that, among 6,304 patients aged 5-65 years in China, the prevalence of positive skin prick responses was $14.0 \%$ for dog extract. In addition, given the population's frequent contact with dogs, the incidence of allergic diseases in children is increasing. Among 153 recruited Chinese children with infant food protein allergies, 114 (74.51\%) manifested skin symptoms such as atopic dermatitis or urticaria, and $28(18.30 \%)$ were presented with early respiratory symptoms (18). However, except for Can $\mathrm{f} 6$ (3), there have been few studies regarding specific dog allergens in China, particularly for Can $f$, although these may seriously impact children's health.

Identification of an allergen's 3D structure can be used to understand the body's immune response to allergenic proteins, including cross-reactivity between allergens (19). Furthermore, predicting the secondary structure of a protein from its amino acid sequence is an important step in predicting its 3D structure (20). B cell epitopes show fundamental differences depending on the location of the allergen molecule and the subsequent initiation of the immune response. B cell epitopes can be linear or conformational, and they are usually located on the surface of allergens for easy binding to antibodies. The primary purpose of epitope prediction is to design and propose hypoallergenic molecules that can replace crude allergen extracts. Therefore, identification of $\mathrm{B}$ cell epitopes in Can $f 7$ may aid the design of novel therapeutic modalities and diagnostic tests for canine allergies $(21,22)$. Overall, these results could provide critical information regarding the distribution and characteristics of canine allergies and provide a foundation for improving the diagnosis and treatment of canine allergies in Chinese children.

\section{Patients and methods}

Patients and samples. Twenty pediatric patients with positive skin prick test results (allergens were supplied by ALK-Abelló, Inc., Hørsholm, Denmark) and positive serum IgE test results to dog extracts [via ImmunoCAP assay (Pharmacia Diagnostics AB, Uppsala, Sweden) as described previously (23)], as well as six healthy children, were recruited for the present study. Clinical information for these patients, including specific IgE levels, is shown in Table I. Serum samples $(4 \mathrm{ml})$ were collected from peripheral venous blood from each patient and healthy participant after centrifugation at $2,000 \mathrm{xg}$ for $10 \mathrm{~min}$ at $4^{\circ} \mathrm{C}$. The present study was approved by the Ethics Committee of the First Affiliated Hospital of Nanjing Medical University (2015-SRFA-055). According to the Declaration of Helsinki, all participants written consent was obtained from their parents or legal guardians for the use of their blood samples prior to admission.

Expression and purification of Can $f 7$ in Escherichia coli (E. coli). Can f 7 has 450 base pairs and encodes 149
Table I. Information of participants.

\begin{tabular}{|c|c|c|c|c|}
\hline No. & Sex & Age & $\begin{array}{c}\text { ImmunoCAP } \\
(\mathrm{KU} / \mathrm{L})\end{array}$ & $\begin{array}{c}\text { Associated } \\
\text { disease }\end{array}$ \\
\hline 1 & Female & 1 & 0.96 & Asthma \\
\hline 2 & Female & 1 & 59.6 & Asthma \\
\hline 3 & Male & 2 & 2.16 & Pollinosis \\
\hline 4 & Female & 3 & 91.7 & Asthma, rhinitis \\
\hline 5 & Female & 4 & 5.61 & Rhinitis \\
\hline 6 & Female & 5 & 13.8 & Asthma, rhinitis \\
\hline 7 & Female & 6 & 21.1 & Rhinitis \\
\hline 8 & Male & 6 & 56.1 & Asthma, rhinitis \\
\hline 9 & Male & 7 & 31.3 & Rhinitis \\
\hline 10 & Male & 7 & 18.4 & Asthma \\
\hline 11 & Female & 7 & 9.85 & Asthma, rhinitis \\
\hline 12 & Female & 8 & 24.5 & Cough \\
\hline 13 & Female & 8 & $>100$ & Asthma \\
\hline 14 & Male & 9 & 17.3 & Rhinitis \\
\hline 15 & Male & 9 & 63.6 & Asthma \\
\hline 16 & Female & 10 & 77.4 & Asthma \\
\hline 17 & Female & 10 & 20.2 & Dermatitis \\
\hline 18 & Female & 11 & 13.9 & Asthma, rhinitis \\
\hline 19 & Female & 12 & 8.57 & Asthma, rhinitis \\
\hline 20 & Female & 12 & 36.6 & Rhinitis \\
\hline N1 & Female & 9 & 0.37 & None \\
\hline N2 & Male & 11 & 0.57 & None \\
\hline N3 & Male & 11 & 0.48 & None \\
\hline N4 & Male & 14 & 0.22 & None \\
\hline N5 & Female & 16 & 0.32 & None \\
\hline N6 & Male & 16 & 0.44 & None \\
\hline
\end{tabular}

amino acids (GenBank accession no. 945178). The Can f 7 gene was synthesized (GenScript, Nanjing, China) using the GenScript rare codon analysis tool (www.genscript. com/tools/rare-codon-analysis/), optimized on the basis of constant amino acid sequences, subcloned into the pET-28a vector via NcoI and XhoI sites and verified by DNA sequencing (24).

The pET28a-Can $\mathrm{f} 7$ plasmid was transformed into BL21 (DE3) pLysS E. coli cells. Positive colonies were selected and incubated overnight at $37^{\circ} \mathrm{C}$. All broths were inoculated into $200 \mathrm{ml}$ of LB-Kanamycin broth and cultured with shaking at $37^{\circ} \mathrm{C}$ until the optical density value at $600 \mathrm{~nm}$ reached 0.6-0.8. Isopropyl- $\beta$-D-thiogalactopyranoside (Takara Bio, Inc., Otsu, Japan) was added to a final concentration of 0.5 $\mathrm{mM}$ in the broth and incubated for a further $16 \mathrm{~h}$. Bacterial cells were pelleted by centrifugation at $2,000 \mathrm{x} \mathrm{g}$ for $30 \mathrm{~min}$ at $4^{\circ} \mathrm{C}$, and the pellet was collected. The pellet was lysed in lysis buffer $\left(50 \mathrm{mM} \mathrm{NaH} \mathrm{PO}_{4}, 300 \mathrm{mM} \mathrm{NaCl}, \mathrm{pH} \mathrm{8.0)}\right.$ by sonication with 50 short bursts of $10 \mathrm{sec}$ at $100 \mathrm{~W}$ and a $10 \mathrm{sec}$ cooling period between each burst. The lysate was centrifuged at $13,523 \mathrm{x} \mathrm{g}$ for $30 \mathrm{~min}$ at $4^{\circ} \mathrm{C}$. As recombinant Can $\mathrm{f} 7$ is mainly found in inclusion bodies, inclusion bodies were harvested by centrifugation at $13,523 \mathrm{x} \mathrm{g}$ for $20 \mathrm{~min}$ at $4^{\circ} \mathrm{C}$. After solubilizing the inclusion bodies with $8 \mathrm{M}$ urea, 
the supernatant was applied to High Affinity Ni-NTA Resin (GenScript, Nanjing, China), then the resin was washed with a buffer containing $20 \mathrm{mM}$ Tris- $\mathrm{HCl}, 100 \mathrm{mM} \mathrm{NaH} \mathrm{PO}_{4}$, $10 \mathrm{mM}$ imidazole, and $8 \mathrm{M}$ urea, and eluted with a buffer containing $100 \mathrm{mM} \mathrm{NaH} \mathrm{PO}_{4}, 500 \mathrm{mM}$ imidazole, and $8 \mathrm{M}$ urea, $\mathrm{pH} 8.0$ (25). Eluted fractions were collected and reduced overnight by adding a final concentration of $50 \mathrm{mM}$ dithiothreitol. Refolding was performed via 1:50 dilution of the denatured protein in a redox refolding buffer $(0.05 \mathrm{mg} / \mathrm{ml}$ final concentration) consisting of $0.1 \mathrm{M}$ Tris, $\mathrm{pH} 8.5,0.5$ Ml-arginine, $1 \mathrm{mM}$ EDTA, $5 \mathrm{mM}$ reduced glutathione (GSH) and $1 \mathrm{mM}$ oxidized glutathione (GSSG) for $48 \mathrm{~h}$ at $15^{\circ} \mathrm{C}$. The refolded rCan $\mathrm{f} 7$ was dialyzed against $\mathrm{PBS}(\mathrm{pH}$ 7.4), and the supernatant was concentrated using Amicon ${ }^{\circledR}$ Ultra $15 \mathrm{ml}$ Centrifugal Filters (MWCO 3 kDa; Merck KGaA, Darmstadt, Germany), the final concentration was $0.3 \mathrm{mg} / \mathrm{ml}$.

Circular dichroism (CD) analysis of rCan $f 7$ expressed in $E$. coli. CD analysis of rCan $\mathrm{f} 7$ was carried out using a Chirascan CD spectrometer (Applied Photophysics Ltd., Surrey, UK). To record far ultra violet $C D(200-250 \mathrm{~nm})$ spectra, $0.1 \mathrm{mg} / \mathrm{ml}$ refolded Can $\mathrm{f} 7$ in PBS was analyzed in a $10-\mathrm{mm}$ path-length quartz cuvette at a $1 \mathrm{~nm}$ bandwidth and $0.5 \mathrm{sec}$ per point. The final spectra were averaged from three consecutive scans and baseline-corrected by subtracting a control PBS spectrum. The results were expressed as the mean residue ellipticity in $\operatorname{deg} \mathrm{xcm}^{2} \mathrm{x} \mathrm{dmol}^{-1}$ and analyzed using the K2D3 program (cbdm-01.zdv.uni-mainz.de/ andrade/k2d3/) (26).

IgE binding activity of Can $f 7$ identified by western blot analysis. Western blot analysis was used to detect the IgE-binding activity of Can $\mathrm{f} 7$. Recombinant Can $\mathrm{f} 7$ (2 $\mu \mathrm{g})$ was separated by $13 \%$ SDS-PAGE and then transferred to a polyvinylidene difluoride (PVDF) membrane (Merck KGaA, Darmstadt, Germany). The PVDF membrane was then blocked with $5 \%$ skim milk for $2 \mathrm{~h}$ at room temperature and subsequently incubated with sera from 20 children with dog allergies [diluted 1:20 in Tris-buffered saline Tween-20 (TBST)] as the primary antibody and incubated overnight at $4^{\circ} \mathrm{C}$. After washing with TBST, the membrane was incubated with horseradish peroxidase (HRP)-conjugated goat anti-human IgE monoclonal antibody (cat. no. 074-1004; KPL, Inc., Gaithersburg, MD, USA) diluted 1:5,000 in TBST for 1 $\mathrm{h}$ at room temperature. Positive protein bands were visualized by incubating the membrane with Immobilon ${ }^{\mathrm{TM}}$ Western HRP Substrate Luminol Reagent (Merck KGaA). Six healthy children's sera were used as negative controls and PBST were used as a blank control.

Immunoreactivity of human sera with recombinant Can $f 7$ by ELISA. A 96-well microplate (Corning Inc., NY, USA) was coated with $100 \mu 110 \mu \mathrm{g} / \mathrm{ml}$ recombinant Can $\mathrm{f}$ 7 in PBS and incubated at $4^{\circ} \mathrm{C}$ overnight. The wells of the plate were then blocked with bovine serum albumin (BSA; Biosharp, Hefei, China; $1 \mathrm{mg} / \mathrm{ml} ; 200 \mu \mathrm{l} /$ well) for $1 \mathrm{~h}$ at $25^{\circ} \mathrm{C}$ and washed once with PBS-0.05\% Tween-20 (PBST). Subsequently, $100 \mu \mathrm{l}$ of the $20 \mathrm{Can} \mathrm{f} 7$-allergic children's sera (1:10 dilution in PBST with $0.1 \%$ BSA) was incubated for $2 \mathrm{~h}$ at $25^{\circ} \mathrm{C}$. After incubation, the wells were washed three times with PBST and incubated with HRP-conjugated goat anti-human IgE monoclonal antibody $(1: 2,500)$ for $1 \mathrm{~h}$ at $25^{\circ} \mathrm{C}$. Subsequently, the wells of the plate were washed and incubated with $100 \mu 1$ Tetramethylbenzidine (TMB) substrate solution (Nanjing KeyGEN Biotech Co., Ltd., Nanjing, China). After incubating for $30 \mathrm{~min}$ at room temperature, the reaction was stopped by adding $50 \mu 12$ $\mathrm{M} \mathrm{H}_{2} \mathrm{SO}_{4}$ in the wells. The absorbance value was then read at $450 \mathrm{~nm}$ on a Eon microplate spectrophotometer (BioTek Instruments Inc., Winooski, VT, USA; www.biotek.com/). Sera from six healthy subjects were used as control normal human serum (NHS). Absorbance values were regarded as positive if they have statistical significance compared to the mean value of the healthy controls.

Basophil activation analysis. Allergens induce protein expression levels of the Cluster of differentiation (CD)63 and the $\mathrm{C}-\mathrm{C}$ motif chemokine receptor (CCR) 3 on basophils which is considered an indicator of basophil activation (27). The ability of rCan $\mathrm{f} 7$ to activate basophils in a modified basophil activation test, was examined (28-31). Briefly, a total of $4.3 \times 10^{7}$ peripheral blood mononuclear cells were obtained from $20 \mathrm{ml}$ of blood collected from healthy individuals using a Ficoll-Paque density gradient (GE Healthcare, Uppsala, Sweden) according to the manufacturer's protocol. Then, the cells were incubated with $10 \mathrm{ml}$ of lactic acid buffer (containing $1.3 \mathrm{M} \mathrm{NaCl}, 0.005$ $\mathrm{M} \mathrm{KCl}$ and $0.01 \mathrm{M}$ lactic acid, $\mathrm{pH}$ 3.9) for 2 min on ice. After neutralization with $12 \%$ Tris ( $\mathrm{pH} 10.9$ ), nonspecific IgE on basophils was removed. The cells were washed and aliquots of a cell suspension were passively sensitized by incubation in RPMI-1640 medium (Thermo Fisher Scientific, Inc., Waltham, MA, USA) containing $10 \%$ patient serum for $2 \mathrm{~h}$ at $37^{\circ} \mathrm{C}$. The six serum groups used in this test consisted of six patients' sera (No. 2, No. 4, No. 6, No. 13, No. 17 and No. 20 in Table I) and six normal sera. The cells were then incubated with Can $\mathrm{f} 7$ (1.0 $\mu \mathrm{g} / \mathrm{ml}$ ) for $15 \mathrm{~min}$ at $37^{\circ} \mathrm{C}$. HRP-conjugated goat anti-human IgE antibody $(1.0 \mu \mathrm{g} / \mathrm{ml})$ was used as a positive control. After incubation, the cells were washed and resuspended in $100 \mu \mathrm{l}$ stain buffer, then $20 \mu \mathrm{l}$ of anti-human CD63-FITC antibody (cat. no. MA1-19602; Invitrogen, Camarillo, CA, USA) and $5 \mu \mathrm{l}$ of CCR3-PE-labeled antibody (cat. no. A18365; eBioscience, Inc., San Diego, CA, USA) were added to the cells for $15 \mathrm{~min}$ at $37^{\circ} \mathrm{C}$ in the dark. Surface-labeled flow cytometric analysis was performed on a FACSAria flow cytometer at 488 $\mathrm{nm}$ and analyzed with FACSDiva software v.6.1.3 (both BD Biosciences, Franklin Lakes, NJ, USA) (32).

Structure modeling and B cell epitopes prediction. A structural model of Can $\mathrm{f} 7$ protein was generated by aligning patterns in SWISS-MODEL (swissmodel.expasy.org/interactive) (33). Briefly, the amino acid sequences of Can $f 7$ were used to search the homologous template. A template for Can $\mathrm{f} 7$ was selected from the SWISS-MODEL server (34). TMFMM 2.0 software (http://www.cbs.dtu.dk/services/TMHMM/) can predict transmembrane helices of Can $\mathrm{f} 7$ (35). The secondary structure of Can f 7 ( $\alpha$-helix, $\beta$-sheet, and random coil) was predicted using the PyMOL molecular graphics system (pymol.org/2/) (36).

Using the DNAStar (www.dnastar.com/) protean system, the BepiPred 2.0 server (www.cbs.dtu.dk/services/BepiPred/) and the BPAP system (imed.med.ucm.es/Tools/antigenic. 
After

Before

61

After

Before

121

After

Before

181

After

Before

241

After

Before

301

After

Before

361

After

Before

421

After

Before
ATGCGTCTGCTGGTGCTGCTTCCTGCTGCTGGCTCTGGGTGACCTGGGTCCGGGTGGT ATGCGTCTCTTGGTCGCCGCGTTCCTGCTCCTGGCGCTCGGCGACCTCGGCCCTGGCGGA

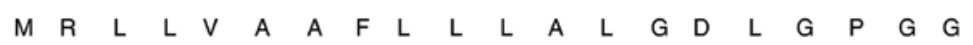

GCTGTTCACTTCAAAGACTGCGGTTCTGCTGTTGGTGTTATCAAAGAACTGAACGTTAAC GCGGTGCATTTCAAGGACTGTGGTTCTGCAGTTGGAGTTATAAAAGAACTGAATGTGAAC

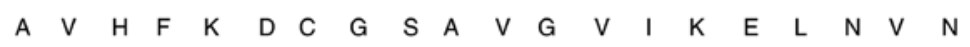

CCGTGCCCGGCTCAGCCGTGCAAACTGCACAAAGGTCAGTCTTACTCTGTTAACGTTACC CCATGCCCTGCCCAGCCTTGCAAACTGCACAAAGGCCAATCTTACAGTGTCAATGTCACC

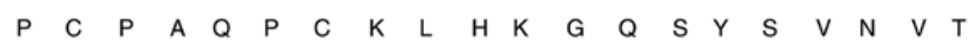

240

TTCACCTCTAACATCCCGTCTCAGTCTTCTAAAGCTGTTGTTCACGGTATCGTTCTGGGT TTCACCAGTAATATTCCATCTCAAAGTAGCAAAGCCGTGGTGCATGGCATCGTGTTGGGC

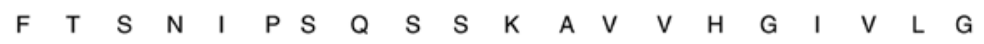
GTTGCTGTTCCGTTCCCGATCCCGGAAGCTGACGGTTGCAAATCTGGTATCAACTGCCCG GTCGCAGTTCCCTTTCCCATTCCTGAGGCTGATGGTTGTAAGAGTGGAATCAACTGCCCC

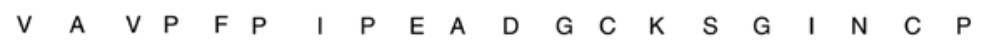

ATCCAGAAAGATAAGACCTACAGCTACCTGAACAAACTGCCAGTGAAGAACGAATACCCC ATCCAGAAAGATAAGACCTACAGCTACCTGAACAAACTGCCAGTGAAGAACGAATACCCC

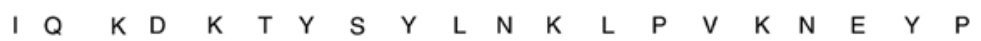

TCTATCAAACTGGTTGTTCAGTGGATGCTGCTGGGTGACAACAACCAGCACCTGTTCTGC TCTATAAAACTGGTGGTGCAGTGGATGCTTCTGGGCGACAACAATCAGCATCTCTTCTGC

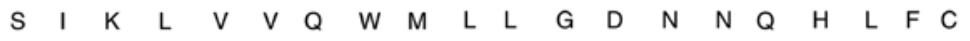
450

TGGGAAATCCCGGTTCAGATCGAAGGTTAA TGGGAAATCCCAGTTCAGATTGAAGGCTAG

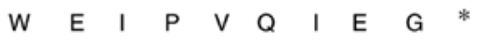

Figure 1. Codon-optimized Can $\mathrm{f} 7$ nucleotide sequences prior to and following codon optimization. Can $\mathrm{f} 7$, Canis familiaris.

pl) predicted B cell epitopes of Can $\mathrm{f} 7(37,38)$. The final consensus epitope results were obtained by combining the results of these three tools with previous methods (39-41). In the DNAStar Protean system, four properties (hydrophilicity, flexibility, accessibility and antigenicity) of the amino acid sequence were chosen as parameters for epitope prediction. Peptide regions with good hydrophilicity, high sensitivity, surface accessibility, and high antigen index were selected as candidate epitopes for further study. The BPAP system and the BepiPred 2.0 server require only amino acid sequences, which provide more direct results, together with the physicochemical properties of amino acids, such as hydrophilicity, flexibility, accessibility, corners and exposed surfaces. Five predicted B cell epitopes were synthesized by GenScript with a purity $>90 \%$ and named as P1, P2, P3, P4 and P5 respectively.

Verification of B cell epitopes by ELISA. The IgE binding of the predicted B cell peptides was detected using ELISA (42). A 96-well microplate was coated with each epitope in PBS at 2 $\mu \mathrm{g} / 100 \mu \mathrm{l} / \mathrm{well}(0.02 \mu \mathrm{g} / \mu \mathrm{l})$. The plate was then blocked with 1 $\mathrm{mg} / \mathrm{ml} \mathrm{BSA}(200 \mu \mathrm{l} / \mathrm{well})$ for $1 \mathrm{~h}$ at $25^{\circ} \mathrm{C}$ and washed once with PBST. Subsequently, $100 \mu 1$ of four Can $\mathrm{f} 7$ allergic children's sera (No. 2, No. 4, No. 6 and No. 13 in Table I; diluted 1:10 in
PBST with $0.1 \%$ BSA) was incubated for $2 \mathrm{~h}$ at $25^{\circ} \mathrm{C}$. After incubation, the plates were washed three times with PBST. The plates were incubated with a 1:2,500-diluted HRP-conjugated goat anti-human IgE monoclonal antibody for $1 \mathrm{~h}$ at $25^{\circ} \mathrm{C}$ and washed with PBST three times. Subsequently, $100 \mu 1 \mathrm{TMB}$ color liquid was added to each well. After staining for $30 \mathrm{~min}$ at room temperature, the reaction was stopped by the addition of $50 \mu 1$ of $2 \mathrm{M} \mathrm{H}_{2} \mathrm{SO}_{4}$, and the serum of four healthy participants without a history of allergic symptoms was used as control, NHS. After incubation, plates were processed as described above, and absorbances were read at $450 \mathrm{~nm}$.

ELISA inhibition of B cell epitopes. The five B cell epitopes, BSA and the rCan $\mathrm{f} 7$ were tested via inhibition ELISAs of Can $\mathrm{f} 7$ with the sera of two Can $\mathrm{f} 7$-allergic children (No. 4 and No. 13 in Table I). In this experiment, 96-well microplates were coated with $2 \mu \mathrm{g}$ recombinant Can $\mathrm{f} 7$ (100 $\mu 1 /$ well) in PBS overnight $4^{\circ} \mathrm{C}$. The plate was washed three times with PBST. The plate was then blocked with BSA (1 $\mathrm{mg} / \mathrm{ml} ; 200 \mu \mathrm{l} /$ well) for $1 \mathrm{~h}$ at $25^{\circ} \mathrm{C}$ and washed once with PBST. The plates were then incubated with $100 \mu 1$ of 2 allergic children's sera (1:10 diluted in PBST, which were previously preincubated with synthesized epitopes for $1 \mathrm{~h}$ at $37^{\circ} \mathrm{C}$ with 8 gradient concentrations $\left(0,10^{-4}, 10^{-3}, 10^{-2}, 10^{-1}\right.$, 
1,10 , and $10^{2} \mu \mathrm{g} / \mathrm{ml}$ ) at $25^{\circ} \mathrm{C}$ for $2 \mathrm{~h}$. After incubation, the plates were washed three times with PBST. The plates were incubated with a 1:2,500-diluted HRP-labeled anti-human IgE monoclonal antibody for $1 \mathrm{~h}$ at $25^{\circ} \mathrm{C}$ and washed with PBST three times. Subsequently, $100 \mu 1$ TMB color liquid was added to each well. After staining for $30 \mathrm{~min}$ at room temperature, the reaction was stopped by the addition of 50 $\mu \mathrm{l}$ of $2 \mathrm{M} \mathrm{H}_{2} \mathrm{SO}_{4}$. After incubation, plates were processed as described above, and the absorbance was read at $450 \mathrm{~nm}$ (43).

Statistical analysis. Statistical significance between mean values of three experiments was analyzed by Dunnett's t-test following one-way analysis of variance or the Student's t-test utilizing the SPSS 13.0 version (SPSS, Inc., Chicago, IL, USA). $\mathrm{P}<0.05$ was considered to indicate a statistically significant difference.

\section{Results}

Expression and purification of Can $f 7$ in E. coli. The optimized codon sequence of Can $\mathrm{f} 7$ used for expression in $E$. coli is shown in Fig. 1. The codon-optimized Can $\mathrm{f} 7$ gene was then subcloned into the pET-28a (+) vector and transformed into BL21 (DE3) pLysS E. coli cells. Fig. 1 shows a comparison of the sequences prior and following optimization. By SDS-PAGE, Can 7 was shown to be primarily expressed in inclusion bodies (Fig. 2A). Recombinant Can $f$ was then purified on a Ni-NTA resin under denaturing conditions. Purified Can $\mathrm{f} 7$ is shown as a single band in the subsequent SDS-PAGE analysis. The apparent molecular weight of purified recombinant Can $\mathrm{f} 7$ was $\sim 14 \mathrm{kDa}$ (Fig. 2B). The denatured proteins were refolded in a glutathione redox system. The far UV spectra of refolded Can $\mathrm{f} 7$ showed a trend towards $\beta$-sheet structures (Fig. 3). Estimation of the secondary structure using the K2D3 program resulted in a determination of $\sim 1.43 \%$ $\alpha$-helices and $44.13 \% \beta$-sheets.

Immunoreactivity of Can $f 7$ to IgE by western blot and ELISA. To determine the ability of Can $\mathrm{f} 7$ to bind specific $\mathrm{IgE}$ in sera from dog-allergic children, western blot analysis and ELISA were performed. A total of 20 pediatric patients with dog allergies were included. As shown in Fig. 4, six of 20 dog-allergic sera from pediatric patients showed positive $\mathrm{IgE}$ binding to Can $\mathrm{f} 7$ (numbers of the positive children are No. 2, 4, 6, 13, 17 and 20 in Table I), whereas healthy control sera failed to do so.

Basophil activation analysis. Can $\mathrm{f} 7$ induced an $\sim 4$.0-fold increase in CD63 and CCR3 expression in basophils sensitized by serum from dog-allergic children compared with healthy controls (Fig. 5).

Structure modeling and B cell epitope prediction. Looking for a protein with a similar amino acid sequences to Can $\mathrm{f}$ 7 in SWISS-MODEL, an epididymal secretory protein E1 (PDB ID: 2hka.1.A; www.rcsb.org/) demonstrated the highest sequence identity with Can $\mathrm{f} 7(76.15 \%)$. Therefore, the template $2 \mathrm{hka} .1$. A was selected as a template for homology
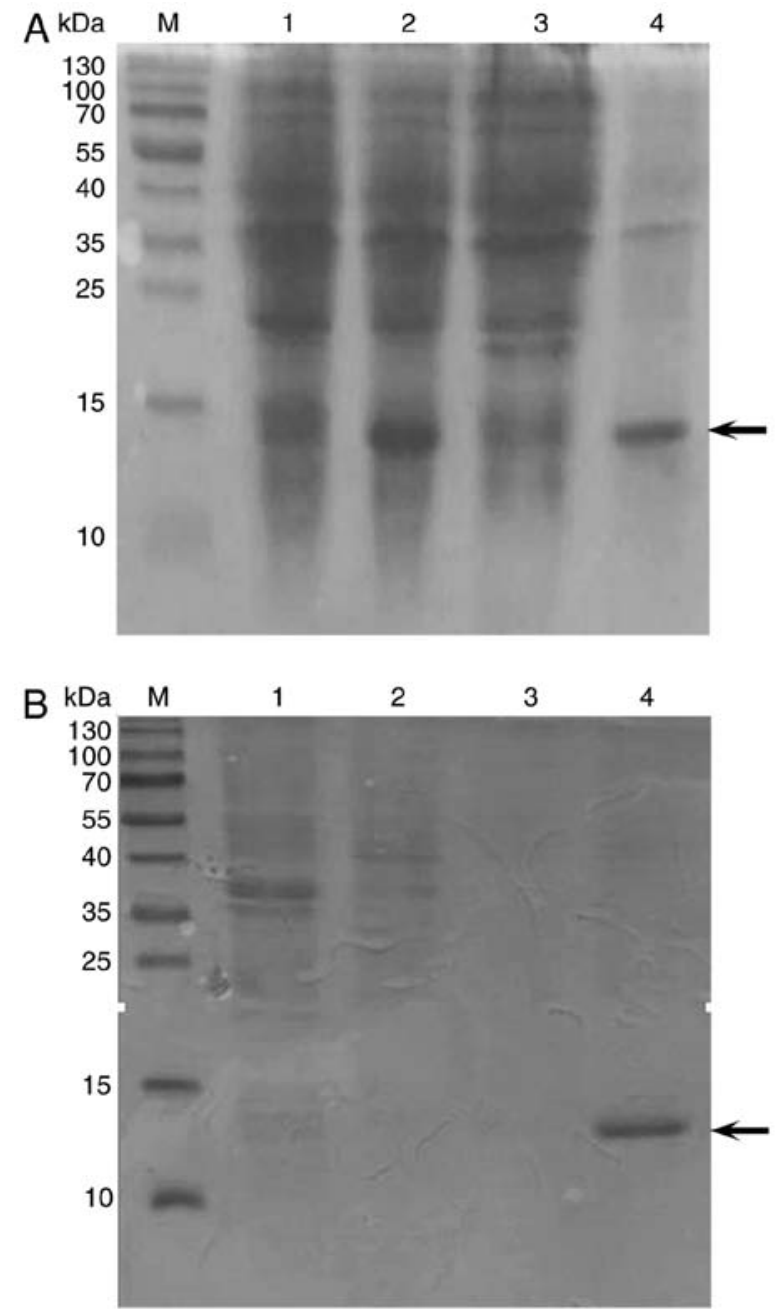

Figure 2. Expression and purification of Can $\mathrm{f} 7$ in E. coli. (A) Lane M, protein molecular weight standard; Lane 1, noninduced recombinant Can f 7 whole cell lysate; Lane 2 , isopropyl- $\beta$-D-thiogalactopyranoside-ind uced recombinant Can f 7 whole cell lysate; Lane 3, supernatant fraction after ultrasonication; Lane 4, precipitated fraction (inclusion bodies) after ultrasonication. (B) SDS-PAGE after affinity chromatography of Can $\mathrm{f}$ 7. Lane $\mathrm{M}$, protein molecular weight standard; Lane 1, unbound fractions of the supernatant of Can $\mathrm{f}$ 7; Lane 2, first elution fraction using $500 \mathrm{mM}$ imidazole; Lane 3, second elution fraction using $500 \mathrm{mM}$ imidazole; Lane 4, third elution fraction using $500 \mathrm{mM}$ imidazole. The arrow indicates Can $\mathrm{f} 7$ and its the purified version. Can f7, Canis familiaris.

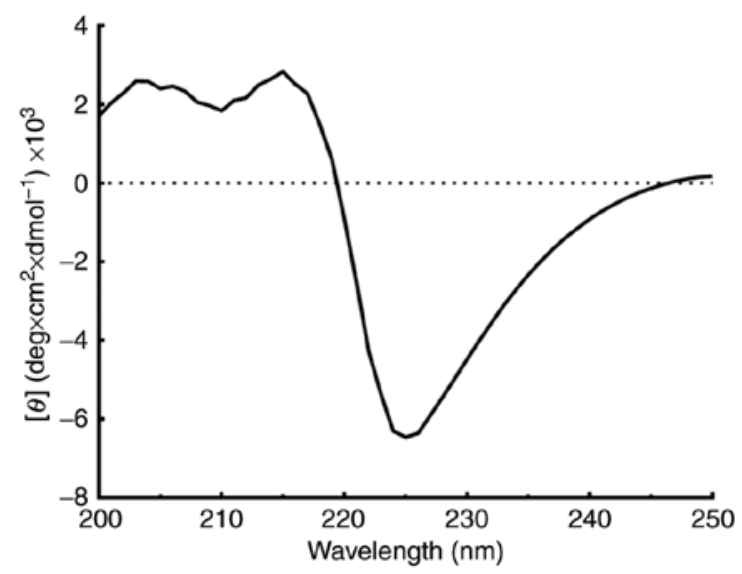

Figure 3. Circular dichroism analysis of recombinant Can $\mathrm{f} 7$ expressed in $E$. coli. The molecular ellipticities (y-axis) at different wavelengths (200-250 nm, X-axis) are displayed. Can f7, Canis familiaris. 

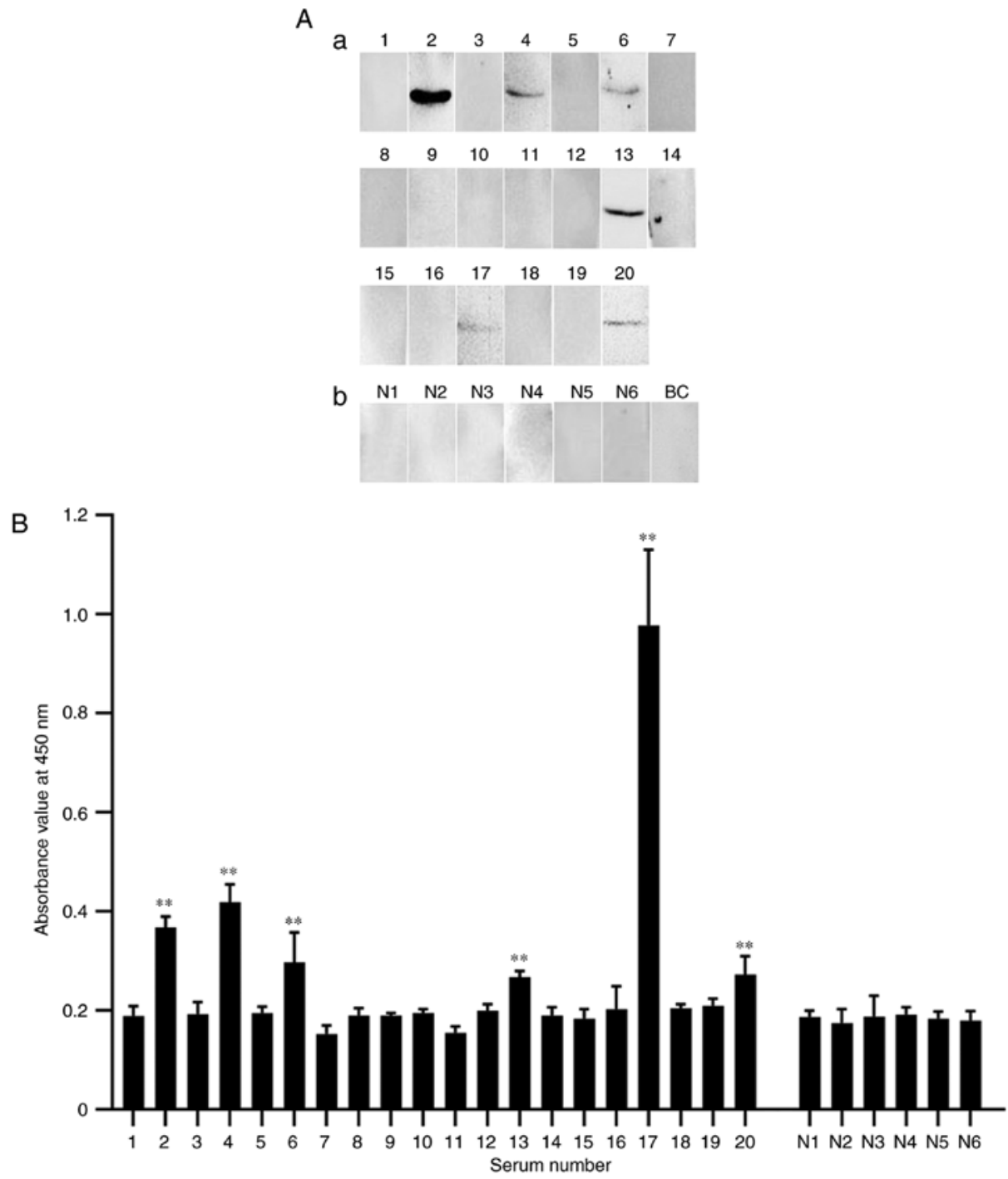

Figure 4. IgE reactivity of human sera against $\mathrm{rCan} f$ 7. (A) IgE binding of Can $\mathrm{f} 7$ identified by western blot analysis. (a) Can $\mathrm{f} 7$ was incubated with sera from 20 dog-allergic patients (line 1-20). (b) Can $\mathrm{f} 7$ was incubated with sera from 6 healthy individuals as negative serum controls (N1-N6) and PBST as BC. (B) Immuno-reactivity of Can $\mathrm{f} 7$ to IgE was assessed by ELISA. The values are shown as the mean \pm standard error from three experiments. ${ }^{* *} \mathrm{P}<0.01 \mathrm{vs}$. the healthy controls. BC, blank control; Can f7, Canis familiaris; Ig, immunoglobin; N, negative; PBST, PBS with Tween-20.

modeling. Fig. 6A shows the overall 3D structure of Can $\mathrm{f} 7$ determined via homology modeling.

Can $\mathrm{f} 7$ was predicted to contain no transmembrane helix by TMHMM 2.0. Secondary structure prediction showed that Can $\mathrm{f} 7$ contains $6 \beta$-sheets and no $\alpha$-helices (Fig. 6B).

Based on four main properties (hydrophilicity, flexibility, reachability and antigenicity), the final predicted B-cell epitopes in Can $\mathrm{f} 7$ allergen by DNAstar were amino acid regions 64-87, 89-106 and 117-127. In contrast, the BPAP system predicted regions 18-29, 65-87, 89-101, 106-117, 120-128 and 136-145 as B cell epitopes in Can $\mathrm{f}$ 7. The BepiPred 2.0 server predicted regions $34-47,88-103,105-118$, and $136-148$ as B cell epitopes in Can $\mathrm{f} 7$. The final potential B cell epitopes of Can $\mathrm{f} 7$ were determined based on the results from all three tools. The final results of the three immunological informatics tools ultimately predicted five B cell epitopes in Can $\mathrm{f} 7$ : P1: IPSQSSKAVVHGIVLGVAVPFPI; P2: EADGCKSGINCPI; P3: TYSYLNKLPVKN; P4: PSIKLVVQW; and P5: QHLFCWEIPV (Table II; Fig. 6C).

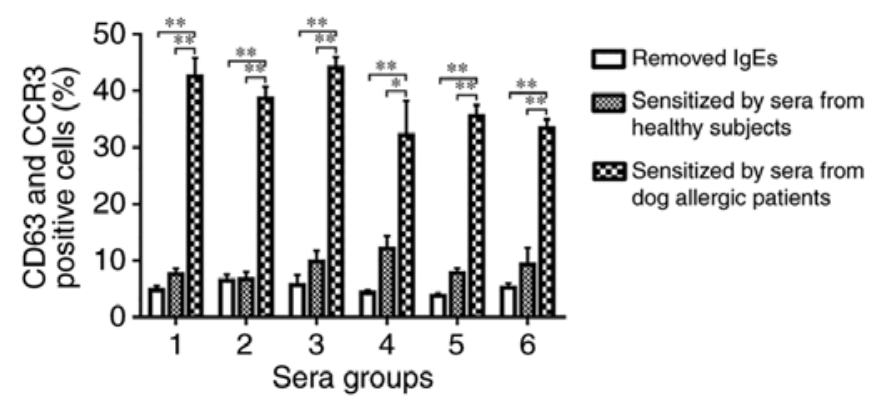

Figure 5. Induction of basophil activation by purified recombinant Can $\mathrm{f} 7$. After removal of nonspecific IgE on basophils, cells from each donor were sensitized with sera from six healthy subjects or six dog-allergic patients and treated with Can f 7 at $1.0 \mu \mathrm{g} / \mathrm{ml}$. The values shown are the mean \pm standard error from six different participants. ${ }^{~} \mathrm{P}<0.05$ and ${ }^{* *} \mathrm{P}<0.01$ vs. the sera derived from the dog allergic patient. Can $\mathrm{f} 7$, Canis familiaris; CCR, C-C motif chemokine receptor; $\mathrm{CD}$, cluster of differentiation; Ig, immunoglobin.

$B$ cell epitope verification. The specific IgE binding of predicted B cell peptides was detected by ELISA using sera 
Table II. Location of the B cell epitopes of the Can $\mathrm{f} 7$ in Canis familaris predicted by immunoinformatics tools.

\begin{tabular}{lcl}
\hline Peptide & Position & \multicolumn{1}{c}{ Sequence } \\
\hline P1 & $65-87$ & IPSQSSKAVVHGIVLGVAVPFPI \\
P2 & $89-101$ & EADGCKSGINCPI \\
P3 & $106-117$ & TYSYLNKLPVKN \\
P4 & $120-128$ & PSIKLVVQW \\
P5 & $136-145$ & QHLFCWEIPV \\
\hline
\end{tabular}

from children with dog allergies (patient No. 2, No. 4, No. 6 and No. 13 in Table I). The results showed that the mean absorbance values in P3 and P4 groups were approximately twice that of the control NHS. However, there was no prominent increase in the absorbance values in P1, P2 and P5 groups. Therefore, among the five predicted $\mathrm{B}$ cell peptides, P3 (TYSYLNKLPVKN) and P4 (PSIKLVVQW) reacted with four dog-allergic children's sera and showed significantly different IgE binding affinity compared with NHS $(\mathrm{P}<0.05$; Fig. 7).

Inhibition ELISA experiments. Inhibition ELISA experiments were performed with the five B cell epitopes, BSA and $\mathrm{rCan} f$ 7. P3 and P4 could inhibit the binding of specific IgE antibodies to the recombinant fusion protein Can $\mathrm{f} 7$. In Patient 4 , the maximum inhibition rates of $\mathrm{P} 3$ and $\mathrm{P} 4$ were $13 \%$ and $17 \%$ at a concentration of $100 \mu \mathrm{g} / \mathrm{ml}$, respectively, whereas $96 \%$ inhibition could be achieved by rCan $\mathrm{f} 7$ (the inhibition rates of $\mathrm{P} 1$, P2, P5 and BSA were $<5 \%$ ). In Patient 13, the maximal inhibition of P3 and P4 were 22 and $26 \%$, respectively. Similarly, the maximal inhibition of rCan 7 was $93 \%$, and the others were all $<10 \%$ (Fig. 8).

\section{Discussion}

To better understand the prevalence and mechanism of Can f 7-associated dog allergy in children in China, recombinant Can $\mathrm{f} 7$ was isolated from E. coli. Can $\mathrm{f} 7$ has three potential glycosylation sites and can reportedly be glycosylated in yeast expression systems (15). However, it has also been reported that glycosylation of Can $\mathrm{f} 7$ does not affect IgE binding to Can $f$ (15). The present study primarily sought to examine the sensitization rate of Can $\mathrm{f} 7$ in Chinese children with allergies to dogs; therefore, glycosylation of the protein was not taken into consideration, which led to the use of the more convenient $E$. coli expression system.

In the present study, Can $\mathrm{f} 7$ was expressed in inclusion bodies, while the same protein was reported to be expressed in a soluble form in $E$. coli (15). This may be due to different factors between the two studies, including the cloning vectors, the optimized codons, the host cells, and the expression conditions, among others. The inclusion bodies were purified on a Ni-NTA column under denaturing conditions. To allow correct folding and disulfide bond formation, a GSH/GSSG redox system was used (44). This system has been widely used for refolding proteins with disulfide bonds (45-47). CD analysis of the refolded Can $\mathrm{f} 7$ found that the secondary structure of this protein was estimated to be $\sim 1.43 \% \alpha$-helix and $44.13 \%$ $\beta$-sheets, which was consistent with the predicted result that Can $f$ contains six $\beta$-sheets.

Can $\mathrm{f} 7$ showed immunological activity, binding with IgE in dog-allergic children's sera with a sensitization rate of 30\% (6/20) in Chinese children. In Fig. 4, not all patients' sera show high reactivity to rCan $\mathrm{f} 7$ since the children were all reacted with dog extracts and then they would be diagnosed with dog allergies. However, dog extracts are complex substances which contain not only Can $\mathrm{f} 7$ but also other allergens, such as Can f 1-6 and even unreported allergens. Thus, not all children were allergic to rCan $\mathrm{f} 7$. This is a preliminary assessment of the IgE-binding activity of dog-allergic children in China and should be confirmed in studies with larger populations in the future. In addition, basophil activation testing, which is well-established as a functional assay for allergenicity was performed. In this test, the expression of CD63 and CCR3 on basophil surfaces is considered an indicator of basophil activation; it was found that Can $\mathrm{f} 7$ could induce up to a 4.0-fold increase in their expression. Therefore, it was confirmed that Can $\mathrm{f} 7$ is an active canine allergen. Compared with a previous study of Can f 7, a major innovation of this experiment is that allergic reactions in Chinese children was analyzed, identifying a higher sensitization rate $(30 \%)$ compared with that $(16.9 \%)$ in a previous report (15). These findings indicate that the sensitization rate of Can $f 7$ is higher in Chinese children than adults and show that Can $\mathrm{f} 7$ is also an important allergen in Chinese children. Taking into account the increase in the number of pet dogs in China, the present analysis of dog allergens is significant.

$\alpha$-Helices and $\beta$-sheets are the two major secondary structures of proteins whose structure is maintained by hydrogen bonding, making it impossible for the epitope sequence to be located therein (3). In contrast, random coils always contain epitope sequences as they are located in areas of surface exposure (48). The secondary structure of Can $\mathrm{f} 7$ is predicted to contain six $\beta$-sheets. In addition to a sequence consisting of $\beta$-sheets, many other residues consist of random coils and may also be associated with certain immunological features of Can $\mathrm{f} 7$. Greater analysis of the structure and function of Can $\mathrm{f} 7$ will likely contribute to improved peptide-based vaccine design for dog allergies.

In this study, B-cell epitopes of Can $\mathrm{f} 7$ were analyzed and projected them on the $3 \mathrm{D}$ structure of Can $\mathrm{f}$ 7. The synthesis of allergen-specific $\operatorname{IgE}$ is a key step in the development of allergic symptoms $(3,49)$. IgE production requires $\mathrm{B}$ cells to be in close contact with allergen-specific helper $\mathrm{T}$ cells for translational recombination (50). Therefore, identification of relevant epitopes is important to understand the development of allergy symptoms. Computer prediction has become a useful method of identifying epitopes from immune-related proteins (51). Hydrophilicity, antigenicity, segmental motility, flexibility and accessibility have all been used to predict linear B cell epitopes on protein sequences based on the propensity values of amino acid properties in many algorithms (43). Actually, conformational epitopes are likely the most significant ones since the results between Fig. 4A and B are not fully consistent. For instance, in Fig. $4 \mathrm{~A}$, serum sIgE from patient 17 shows the lowest reactivity 
A
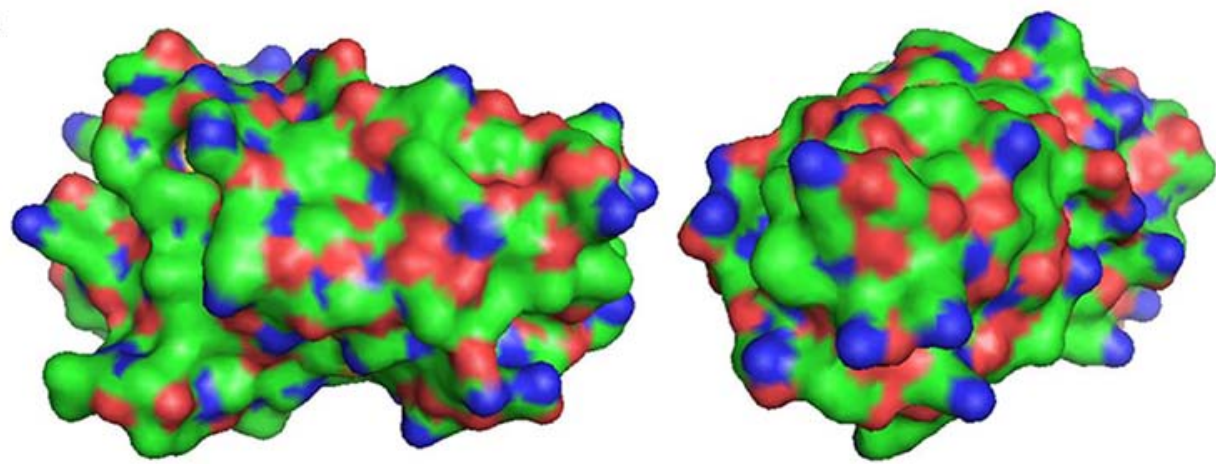

B
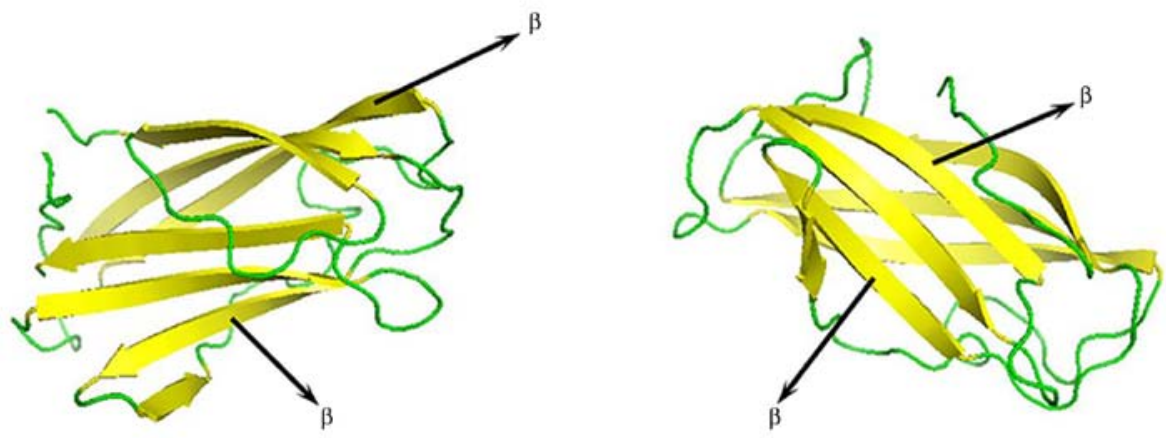

C
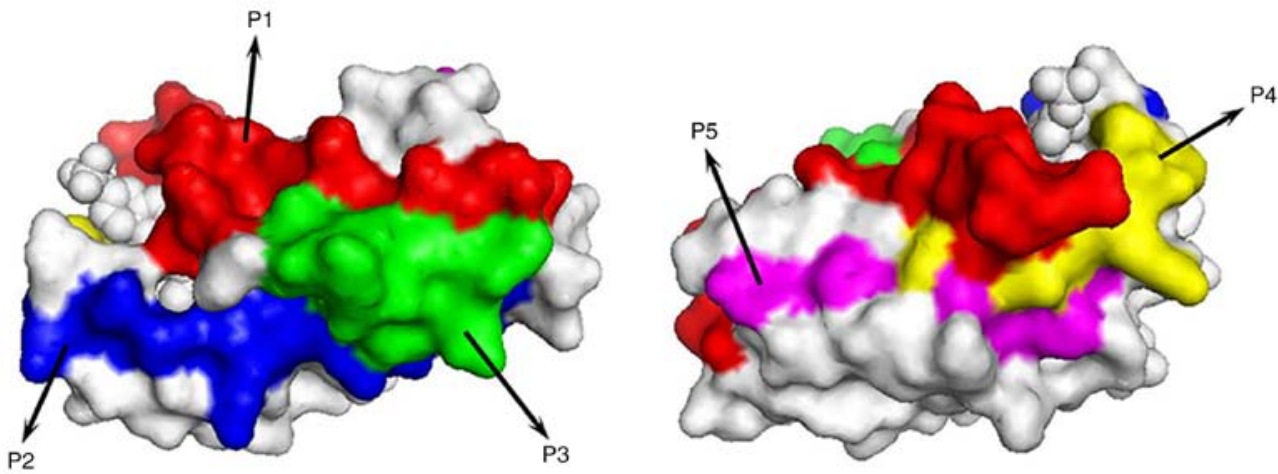

Figure 6. Three-dimensional structure of Can $\mathrm{f}$ 7. (A) Protein structure of a Can $\mathrm{f} 7$ homology model. (B) The predicted secondary structure is shown on the surface of the Can $\mathrm{f} 7$ structure. The green symbolizes $\beta$-sheets (marked with arrows). (C) Predicted B cell epitopes are shown on the surface of the Can $\mathrm{f} 7$ structure (marked with arrows): P1 (red), IPSQSSKAVVHGIVLGVAVPFPI; P2 (blue), EADGCKSGINCPI, P3 (green), TYSYLNKLPVKN; P4 (yellow): PSIKLVVQW, P5 (pink): QHLFCWEIPV. Can f7, Canis familiaris.

to rCan $\mathrm{f} 7$, but in Fig. 4B it shows the highest reactivity. This may due to the conformational epitopes of rCan $\mathrm{f} 7$ were fully destroyed during the sample preparation step in $\mathrm{WB}$ and the $\operatorname{sgE}$ in the serum from patient 17 was mainly target to the conformational epitopes of rCan $\mathrm{f}$ 7. Although the conformational epitopes in allergen play an important role in allergy, their prediction algorithms are still far less than satisfactory (52). Thus, in the present study, the focus was on the prediction of five linear peptides (P1-P5) as potential $B$ cell epitopes of Can $f$ 7. In addition, it was attempted to confirm the predicted allergenicity of these B cell epitopes by ELISA. The present results identified that only P3 and P4 showed a positive association with sera from children with dog allergies. Moreover, these B cell epitopes are composed of consecutive amino acids, meaning that they belong to sequential B cell epitopes. However, although the two predicted epitopes could be detected by $\operatorname{IgE}$ raised against dog allergens, the positive signals in ELISA were relatively weak compared with that of the negative control. This is most likely an artifact of the testing methodology, as a single epitope coated on an ELISA plate has limited ability to bind with Can f 7-specific IgE, which may have led to a weaker ELISA value. The inhibition ELSIA demonstrated that both P3 and P4 could inhibit the binding of specific IgE antibodies to $\mathrm{rCan} \mathrm{f} 7$. In this experiment, the sera from patient 4 and 13 were selected as they had significant reactions to P3 and P4. Moreover, the inhibition rate calculated from the low OD value would lead to large deviation. Therefore, other patient's sera were not included in this experiment. Finally, the present results suggest that sequential epitopes may serve an important role in Can $\mathrm{f}$ 7-related dog allergies.

In summary, Can $\mathrm{f} 7$ recombinant protein was expressed and purified, and its sensitization rate was determined by Western blot, ELISA, and basophil activation analysis. The homology of the Can $\mathrm{f} 7$ protein was modeled, and two B cell epitopes were predicted and confirmed by ELISA. Currently, there is no commercially available method to detect sensitization to Can $\mathrm{f} 7$. The present study provides a potential epitope prediction strategy that may be used for the future diagnosis and treatment of canine allergy in children. 

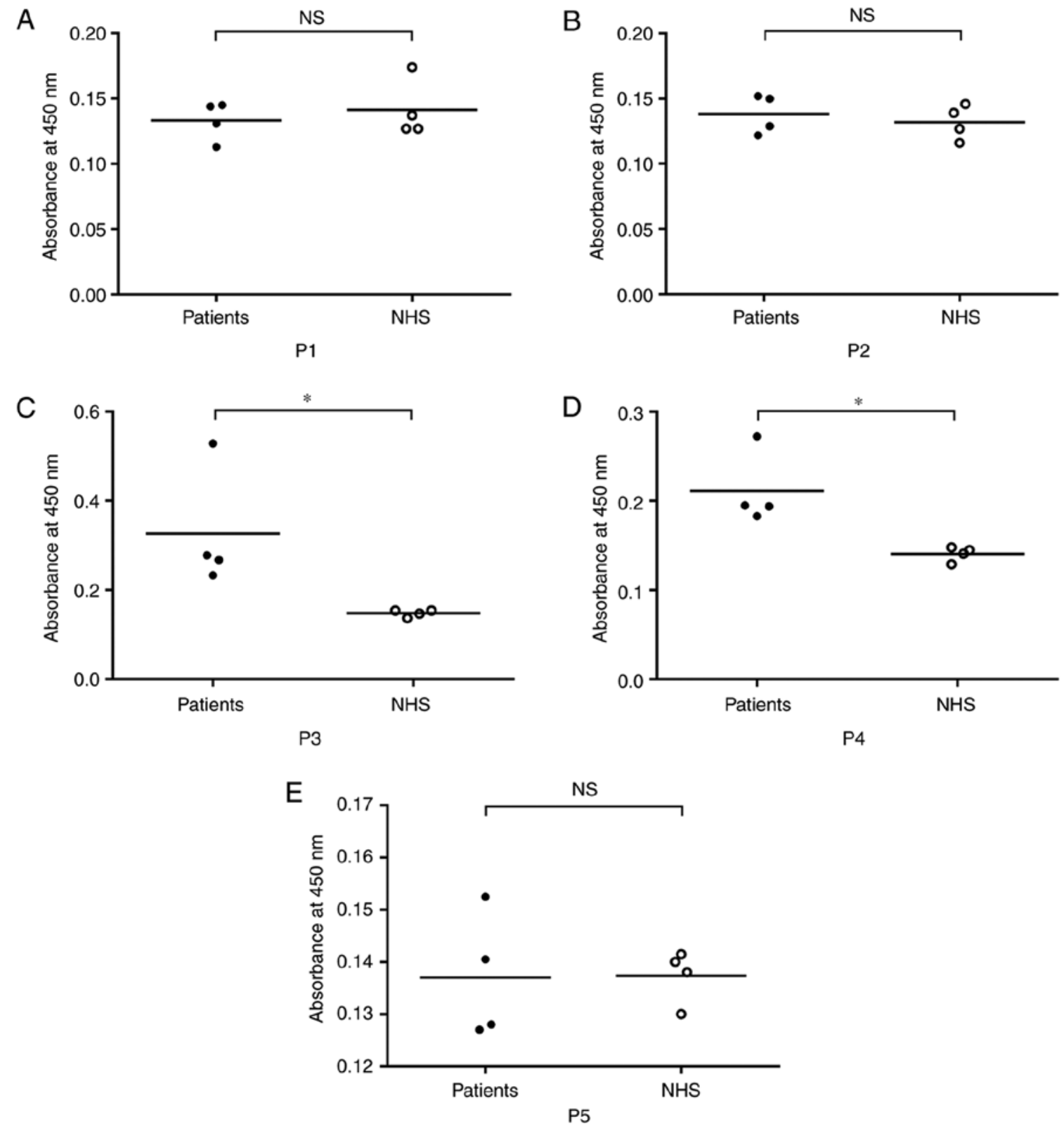

Figure 7. IgE binding of Can $\mathrm{f} 7 \mathrm{~B}$ Cell peptides to sera from dog-allergic children and NHS as detected by ELISA. (A) Dog-allergic children's sera results compared with NHS for P1. (B) Results of dog-allergic children's sera compared with NHS for P2. (C) Results of dog-allergic children's sera compared with NHS for P3. (D) Results of dog-allergic children's sera compared with NHS for P4. (E) Results of dog-allergic children's sera compared with NHS for P5. ${ }^{*} \mathrm{P}<0.05$ vs. NHS. Can f7, Canis familiaris; Ig, immunoglobin; NHS, normal human serum; ns, non-significant.
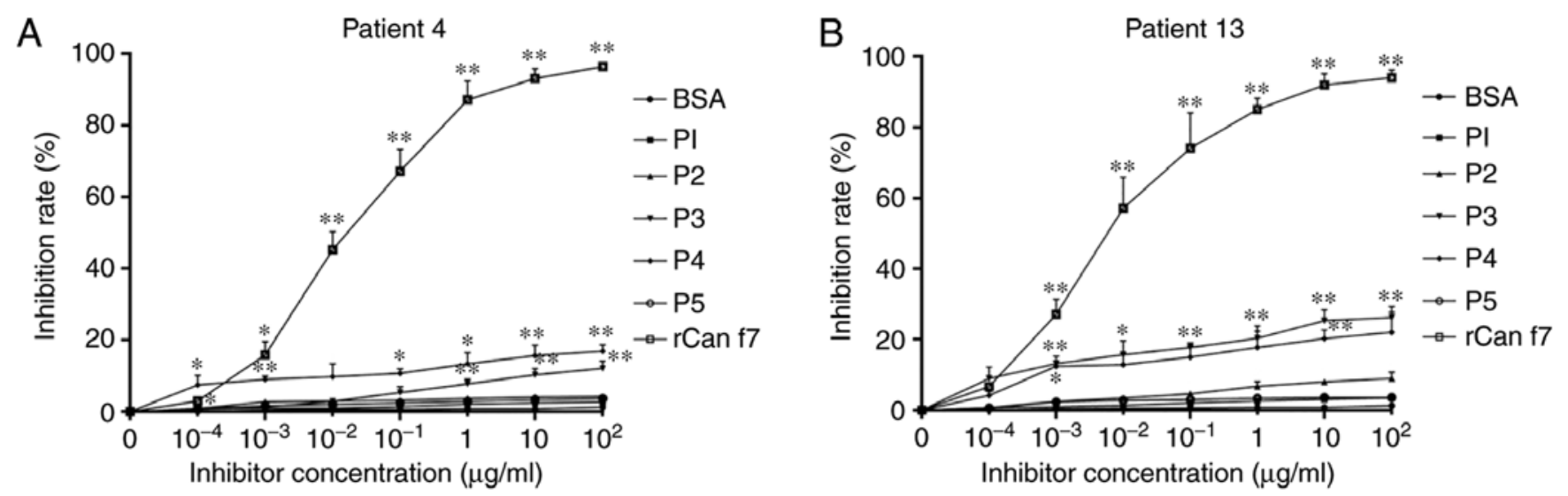

Figure 8. Inhibition ELISA for Can $\mathrm{f} 7$ with two positive B cell epitopes. (A) Results of inhibition experiments in patient 4 and (B) in patient 13 . "P<0.05 and ${ }^{* *} \mathrm{P}<0.01$ in comparison with the uninhibited control. BSA, bovine serum albumin; Can $\mathrm{f} 7$, Canis familiaris; $\mathrm{r}$, recombinant. 


\section{Acknowledgements}

Not applicable.

\section{Funding}

The present study was sponsored by grants from the National Natural Science Foundation of China (grant nos. 81571568, 81771725 and 81871265), the CAMS Innovation Fund for Medical Sciences (CIFMS; no. 2016-I2M-1003), the Innovation team of the Jiangsu provincial Commission of Health and Family Planning (grant no. CXTDA2017049), and the Priority Academic Program Development of Jiangsu Higher Education Institutions.

\section{Availability of data and materials}

All data generated or analyzed during this study are included in this published article.

\section{Authors' contributions}

JLS and JFW contributed to the conception and design of the study. RQW, YJW and ZQX performed all experiments and verified the analytical data. YJZ, MDC and WZ contributed to the statistical analysis and helped to interpret the results. YJW, ZQX and WZ wrote the manuscript. All authors read and approved the final manuscript.

\section{Ethics approval and consent to participate}

The present study was approved by the Ethics Committee of the First Affiliated Hospital of Nanjing Medical University (2015-SRFA-055).

\section{Patient consent for publication}

All participants written consent was obtained from their parents or legal guardians for the use of their blood samples prior to admission.

\section{Competing interests}

The authors declare that they have no competing interests.

\section{References}

1. Konradsen JR, Fujisawa T, van Hage M, Hedlin G, Hilger C, Kleine-Tebbe J, Matsui EC, Roberts G, Rönmark E and Platts-Mills TA: Allergy to furry animals: New insights, diagnostic approaches, and challenges. J Allergy Clin Immunol 135: 616-625, 2015.

2. Nilsson OB, Hage MV and Grönlund H: Mammalian-derived respiratory allergens-Implications for diagnosis and therapy of individuals allergic to furry animals. Methods 66: 86-95, 2014.

3. Wang YJ, Li L, Song WJ, Zhou YJ, Cao MD, Zuo XR and Wei JF: Canis familiaris allergen Can $\mathrm{f}$ 6: Expression, purification and analysis of B-cell epitopes in Chinese dog allergic children. Oncotarget 8: 90796-90807, 2017.

4. Polovic N, Wadén K, Binnmyr J, Hamsten C, Grönneberg R, Palmberg C, Milcic-Matic N, Bergman T, Grönlund $\mathrm{H}$ and van Hage M: Dog saliva-an important source of dog allergens. Allergy 68: 585-592, 2013.
5. Vredegoor DW, Willemse T, Chapman MD, Heederik DJJ and Krop EJM: Can $\mathrm{f} 1$ levels in hair and homes of different dog breeds: Lack of evidence to describe any dog breed as hypoallergenic. J Allergy Clin Immunol 130: 904-909.e7, 2012.

6. Burbach GJ, Heinzerling LM, Edenharter G, Bachert C, Bindslev-Jensen C, Bonini S, Bousquet J, Bousquet-Rouanet L, Bousquet PJ, Bresciani M, et al: GA(2)LEN skin test study II: Clinical relevance of inhalant allergen sensitizations in Europe. Allergy 64: 1507-1515, 2009.

7. Schmitz R, Ellert U, Dahm S and Thamm M: Patterns of sensitization to inhalant and food allergens-findings from the german health interview and examination survey for children and adolescents. Int Arch Allergy Immunol 162: 263-270, 2013.

8. Asarnoj A, Ostblom E, Kull I, Lilja G, Pershagen G, Hedlin $G$, van Hage $M$ and Wickman M: Sensitization to inhalant allergens between 4 and 8 years of age is a dynamic process: results from the BAMSE birth cohort. Clin Exp Allergy 38: 1507-1513, 2008.

9. Schou C, Svendsen UG and Løwenstein H: Purification and characterization of the major dog allergen, Can $\mathrm{f} 1$. Clin Exp Allergy 21: 321-318, 1991.

10. Basagaña M, Luengo O, Labrador M, Garriga T, Mattsson L, Lidholm $\mathrm{J}$ and Cardona V: Component-resolved diagnosis of dog allergy. J Investig Allergol Clin Immunol 27: 185-187, 2017.

11. Mattsson L, Lundgren T, Everberg H, Larsson $\mathrm{H}$ and Lidholm J: Prostatic kallikrein: A new major dog allergen. J Allergy Clin Immunol 123: 362-368.e363, 2009.

12. Kamata Y, Miyanomae A, Nakayama E, Miyanomae T, Tajima T, Nishimura K, Tada T and Hoshi H: Characterization of dog allergens Can $f 1$ and Can f 2.2. A comparison of Can $f$ with Can $\mathrm{f} 2$ regarding their biochemical and immunological properties. Int Arch Allergy Immunol 142: 301-308, 2007.

13. Mattsson L, Lundgren T, Olsson P, Sundberg M and Lidholm $\mathrm{J}$ : Molecular and immunological characterization of Can $f$ : A dog dander allergen cross-reactive with a 23\&emsp; $\mathrm{kDa}$ odorant-binding protein in cow dander. Clin Exp Allergy 40: 1276-1287, 2010 .

14. Nilsson OB, Binnmyr J, Zoltowska A, Saarne T, Hage MV and Grönlund $\mathrm{H}$ : Characterization of the dog lipocalin allergen Can f 6: The role in cross-reactivity with cat and horse. Allergy 67: 751-757, 2012.

15. Khurana T, Newmanlindsay S, Young PR and Slater JE: The NPC2 protein: A novel dog allergen. Ann Allergy Asthma Immunol 116: 440-446, 2016.

16. Luo S, Sun Y, Hou J, Kong X, Wang P, Zhang Q and Sundell J: Pet keeping in childhood and asthma and allergy among children in Tianjin area, China. PLos One 13: e0197274, 2018.

17. Li J, Sun B, Huang Y, Lin X, Zhao D, Tan G, Wu J, Zhao H, Cao L and Zhong N; China Alliance of Research on Respiratory Allergic Disease: A multicentre study assessing the prevalence of sensitizations in patients with asthma and/or rhinitis in China. Allergy 64: 1083-1092, 2009.

18. Gao Q, Ren YX, Liu YG, Ma L, Gu XH, Zhang WX, Liu L, Zhai XJ, Xiang L and Shen KL: Allergy march of Chinese children with infantile allergic symptoms: A prospective multi-center study. World J Pediatr 13: 1-6, 2017.

19. Negi SS and Braun W: Cross-React: A new structural bioinformatics method for predicting allergen cross-reactivity. Bioinformatics 33: 1014-1020, 2017.

20. Feng Y, Lin H and Luo L: Prediction of protein secondary structure using feature selection and analysis approach. Acta Biotheor 62: 1-14, 2013.

21. Fanuel S, Tabesh S, Sadroddiny E and Kardar GA: Analysis of predicted B and T-cell epitopes in Der p 23, allergen from Dermatophagoides pteronyssinus. Bioinformation 13: 307-312, 2017.

22. Curin M, Weber M, Hofer G, Apostolovic D, Keller W, Reininger R, Swoboda I, Spitzauer S, Focke-Tejkl M, van Hage M and Valenta R: Clustering of conformational IgE epitopes on the major dog allergen Can f 1. Sci Rep 7: 12135, 2017.

23. Griffiths RLM, El-Shanawany T, Jolles SRA, Selwood C, Heaps AG, Carne EM and Williams PE: Comparison of the performance of skin prick, immunocap, and isac tests in the diagnosis of patients with allergy. Int Arch Allergy Immunol 172: 215-223, 2017.

24. Xue F, Guo H, Hu Y, Liu R, Huang L, Lv H, Liu C, Yang M and Ma L: Expression of codon-optimized plant glycosyltransferase UGT72B14 in escherichia coli enhances salidroside production. Biomed Res Int 2016: 9845927, 2016. 
25. Ni WW, Huang W, Wu DQ, Zhou YJ, Ji CM, Cao MD, Guo M, Sun $\mathrm{JL}$ and Wei JF: Expression and purification of a major allergen, Pla a 1, from Platanus acerifolia pollen and the preparation of its monoclonal antibody. Mol Med Rep 16: 2887-2892, 2017.

26. Louis-Jeune C, Andrade-Navarro MA and Perez-Iratxeta C: Prediction of protein secondary structure from circular dichroism using theoretically derived spectra. Proteins 80: 374-381, 2012

27. Sanz ML, Gamboa PM, Antépara I, Uasuf C, Vila L, Garcia-Avilés C, Chazot M and De Weck AL: Flow cytometric basophil activation test by detection of CD63 expression in patients with immediate-type reactions to betalactam antibiotics. Clin Exp Allergy 32: 277-286, 2002.

28. Wallowitz ML, Chen RJ, Tzen JT and Teuber SS: Using human basophil donors to assess the clinical relevance of sesame 11S Globulin, Ses i 6. J Allergy Clin Immunol 117: S50-S50, 2006.

29. Wallowitz ML, Chen RJ, Tzen JT and Teuber SS: Ses i 6, the sesame 11S globulin, can activate basophils and shows cross-reactivity with walnut in vitro. Clin Exp Allergy 37: 929-938, 2007.

30. An S, Ma D, Wei JF, Yang X, Yang HW, Yang H, Xu X, He S and Lai R: A novel allergen Tab y 1 with inhibitory activity of platelet aggregation from salivary glands of horseflies. Allergy 66: 1420-1427, 2011

31. Wei JF, Yang H, Li D, Gao P and He S: Preparation and identification of Per a 5 as a novel American cockroach allergen. Mediators Inflamm 2014: 591468, 2014

32. Garcia OP and Marin A: Usefulness of the basophil activation test (BAT) in the diagnosis of life-threatening drug anaphylaxis Allergy 65: 1204-1204, 2010.

33. Arnold K, Bordoli L, Kopp J and Schwede T: The SWISS-MODEL workspace: A web-based environment for protein structure homology modelling. Bioinformatics 22: 195-201, 2006.

34. Kiefer F, Arnold K, Künzli M, Bordoli L and Schwede T: The SWISS-MODEL Repository and associated resources. Nucleic Acids Res 37: 387-392, 2009

35. Krogh A, Larsson B, Von HG and Sonnhammer EL: Predicting transmembrane protein topology with a hidden Markov model: Application to complete genomes. J Mol Biol 305: 567-580, 2001

36. Bramucci E, Paiardini A, Bossa F and Pascarella S: PyMod: Sequence similarity searches, multiple sequence-structure alignments, and homology modeling within PyMOL. Bmc Bioinformatics 13 (Suppl 4): S2, 2012.

37. Ni WW, Wang LB, Zhou YJ, Cao MD, Huang W, Guo M, Ji CM, Sun JL and Wei JF: Expression, purification and epitope analysis of Pla a 3 allergen from Platanus acerifolia pollen. Mol Med Rep 16: 2851-2255, 2018

38. Chen H, Yang HW, Wei JF and Tao AL: In silico prediction of the T-cell and IgE-binding epitopes of Per a 6 and Bla g 6 allergens in cockroaches. Mol Med Rep 10: 2130-3136, 2014.

39. Li X, Yang HW, Chen H, Wu J, Liu Y and Wei JF: In Silico prediction of T and B cell epitopes of Der f 25 in Dermatophagoides farinae. Int J Genomics 2014: 483905, 2014.
40. Yang H, Chen H, Jin M, Xie H, He S and Wei JF: Molecular cloning, expression, IgE binding activities andin silicoepitope prediction of Per a 9 allergens of the American cockroach. Int J Mol Med 38: 1795-1805, 2016.

41. Tong X, Guo M, Jin M, Chen H, Li Y and Wei JF: In silico epitope prediction, expression and functional analysis of Per a 10 allergen from the American cockroach. Int J Mol Med 38: $1806-1814,2016$

42. Bublin M, Kostadinova M, Radauer C, Hafner C, Szépfalusi Z, Varga EM, Maleki SJ, Hoffmann-Sommergruber K and Breiteneder H: IgE cross-reactivity between the major peanut allergen Ara h 2 and the non-homologous allergens Ara h 1 and Ara h 3.J Allergy Clin Immunol 3: 118-124, 2013.

43. Govindaraj D, Sharma S, Gaur SN, Lavasa S, Prasad N and Arora N: Immunogenic peptides: B \& T Cell Epitopes of Per a 10 Allergen of Periplaneta americana. Mol Immunol 80: 24-32, 2016.

44. Rudolph $\mathrm{R}$ and Lilie $\mathrm{H}$ : In vitro folding of inclusion body proteins. FASEB J 10: 49-56, 1996.

45. Rattenholl A, Ruoppolo M, Flagiello A, Monti M, Vinci F, Marino G, Lilie H, Schwarz E and Rudolph R: Pro-sequence assisted folding and disulfide bond formation of human nerve growth factor. J Mol Biol 305: 523-533, 2001.

46. Rattenholl A, Lilie H, Grossmann A, Stern A, Schwarz E and Rudolph R: The pro-sequence facilitates folding of human nerve growth factor from Escherichia coli inclusion bodies. Eur J Biochem 268: 3296-3303, 2001

47. Clewes O, Fahey MS, Tyler SJ, Watson JJ, Seok H, Catania C, Cho K, Dawbarn D and Allen SJ: Human ProNGF: Biological effects and binding profiles at TrkA, P75NTR and sortilin. J Neurochem 107: 1124-1135, 2008.

48. Wang DW, Ni WW, Zhou YJ, Huang W, Cao MD, Meng L and Wei JF: Expression, purification and epitope analysis of Pla a 2 allergen from Platanus acerifolia pollen. Mol Med Rep 17: 394-399, 2018

49. Galli SJ and Mindy T: IgE and mast cells in allergic disease. Nat Med 18: 693-704, 2012.

50. Pomes A and Xe A: Relevant B cell epitopes in allergic disease. Int Arch Allergy Immunol 152: 1-11, 2010.

51. Li GF, Wang Y, Zhang ZS, Wang XJ, Ji MJ, Zhu X, Liu F, Cai XP, Wu HW and Wu GL: Identification of immunodominant Th1-type T cell epitopes from Schistosoma japonicum $28 \mathrm{kDa}$ glutathione-S-transferase, a vaccine candidate. Acta Biochim Biophys Sin (Shanghai) 37: 751-758, 2005.

52. Yao B, Zheng D, Liang S and Zhang C: Conformational B-cell epitope prediction on antigen protein structures: A review of current algorithms and comparison with common binding site prediction methods. PLoS One 8: e62249, 2013. 